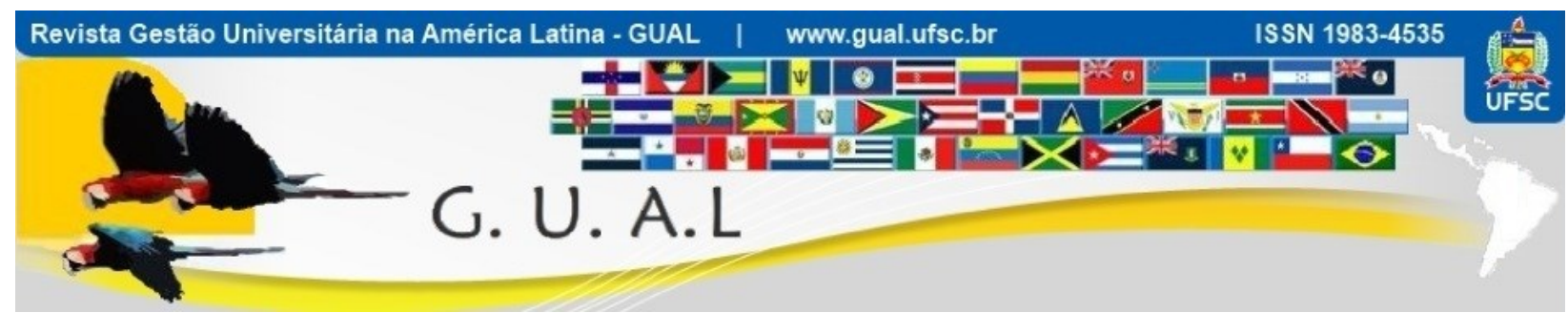

DOI: http://dx.doi.org/10.5007/1983-4535.2018v11n4p20

\title{
EVASÃO, RETENÇÃO E DIPLOMAÇÃO: OCORRÊNCIAS E MOTIVAÇÕES
}

\author{
EVASION, RETENTION AND DIPLOMATION: OCCURRENCES AND \\ MOTIVATIONS
}

\author{
Rafaela Rios, Mestre \\ Universidade Federal de Santa Maria - UFSM \\ rafaelarios@unipampa.edu.br \\ Vânia Medianeira Flores Costa, Doutora \\ Universidade Federal de Santa Maria - UFSM \\ vania.costa@ufsm.br \\ Bruna de Vargas Bianchim, Mestranda \\ Universidade Federal de Santa Maria - UFSM \\ bruna.bianchim@gmail.com \\ Rita de Cássia Trindade dos Santos, Doutoranda \\ Universidade Federal de Santa Maria - UFSM \\ rita.santos0606@gmail.com \\ Aline Mendonça Rodrigues, Graduada \\ Universidade Federal de Santa Maria - UFSM \\ alinemendoncaa@gmail.com
}

Recebido em 24/novembro/2017

Aprovado em 06/setembro/2018

Sistema de Avaliação: Double Blind Review

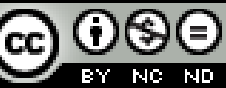

Esta obra está sob uma Licença Creative Commons Atribuição-Uso. 


\title{
RESUMO
}

Este estudo tem por objetivo analisar as ocorrências de evasão, retenção e colação de grau de estudantes de uma instituição federal de ensino. Metodologicamente, trata-se de um estudo de caso, com uma abordagem quali-quantitativa, e de caráter exploratório-descritivo. A organização objeto desse estudo foi uma instituição pública de ensino, multicampi, formada por dez unidades acadêmico-administrativas das quais participaram 543 estudantes. Para análise dos dados auferidos utilizou-se estatísticas descritivas e análise de conteúdo. Os resultados permitiram identificar que muitos fatores influem sobre a evasão, diplomação e retenção acadêmica. $\mathrm{O}$ sucesso e permanência dos estudantes podem estar atrelados a fatores pessoais, fatores didático-pedagógicos, desafios estruturais das cidades etc. Assim faz-se necessário o conhecimento, monitoramento e enfrentamento maciço dessas questões.

Palavras-chave: Ensino Superior. Evasão. Retenção. Diplomação.

\begin{abstract}
This study aims to analyze the occurrences of evasion, retention and graduation of students from a federal teaching institution. Methodologically, this is a case study, with a qualitativequantitative approach, with an exploratory-descriptive character. The organization that was the object of this study was a public teaching institution, multicampi, formed by ten academic-administrative units of which 543 students participated. Descriptive statistics and content analysis were used to analyze the data collected. The results allowed us to identify that many factors influence evasion, graduation and academic retention. The success and permanence of students may be linked to personal factors, didactic-pedagogical factors, structural issues of cities, etc. Thus, it is necessary to acknowledge, track and confront these issues.
\end{abstract}

Keywords: University Education. Evasion. Retention. Degree. 


\section{INTRODUÇÃO}

A ampliação do acesso ao ensino superior nas instituições públicas é uma conquista que envolve diferentes atores sociais na busca pela qualificação profissional, disseminação do conhecimento e construção da cidadania. No Brasil, o Programa de Apoio a Planos de Reestruturação e Expansão das Universidades Federais (REUNI) institucionalizado em 2007 vai ao encontro dessa perspectiva visando uma expansão democrática do acesso ao ensino superior especialmente do contingente de estudantes de camadas sociais de menor renda.

Para Peixoto (2004), essa inclusão social de camadas desfavorecidas da população se tornou uma pauta prioritária para as políticas públicas no enfrentamento das desigualdades econômicas e sociais do País. Nesse sentido, a educação é determinante no processo de construção da cidadania, por isso, deve-se prover aos indivíduos condições para a geração de empregos, qualificação com vistas à inserção no mercado de trabalho participando assim da riqueza coletivamente construída.

Para que essa inclusão aconteça, parece correto afirmar que ao mesmo tempo em que se busca proporcionar o acesso é preciso monitorar os resultados de sua implementação. Rios et al (2016) aponta que alguns fatores como didática pedagógica, questões pessoais dos estudantes, desafios estruturais das cidades influenciam na permanência e sucesso acadêmico. Os autores argumentam que não basta um investimento maciço em assistência estudantil sem um monitoramento e enfrentamento dessas questões.

Januzzi (2005) já salientava a importância do uso de indicadores sociais no ciclo de políticas públicas diante de demandas de interesse programático, pois permite ao longo do tempo a inferência de tendências e a avaliar efeitos de eventuais programas sociais implementados. Desse modo, apropriar-se dos índices de evasão e suas causas bem como a retenção e colação de grau dos estudantes das instituições públicas de ensino que se propõe a inclusão social de um público menos favorecido, evoca a responsabilidade da gestão na prática de monitoramento desses indicadores.

Reis e Matos (2012) defendem a importância do papel do gestor nas organizações públicas visto que cabe a esse a aplicação dos recursos públicos por meio de uma liderança eficaz e de qualidade. Desse modo, tendo presente a importância para a gestão universitária de dispor de informações pertinentes à sua finalidade educativa e de inclusão, o presente artigo tem por objetivo analisar as ocorrências de evasão, retenção e colação de grau de estudantes de uma instituição federal de ensino. 


\section{FUNDAMENTAÇÃO TEÓRICA}

No intuito de embasar teoricamente a proposta desse estudo em analisar as ocorrências de evasão, retenção e colação de grau de estudantes de uma instituição federal de ensino, a presente seção subdivide-se nos seguintes tópicos: o papel do gestor público e breves considerações acerca da evasão, retenção e colação de grau.

\subsection{O PAPEL DO GESTOR PÚBLICO}

Considerando a importância do gestor público na condução das políticas públicas, discorre-se, nesta subseção, sobre seu papel em um contexto de mudanças na administração pública brasileira. Cabe esclarecer, primeiramente, que um administrador ou gestor público é um servidor público investido de um cargo de gerenciamento. Muitos destes cargos são assumidos por profissionais de outras áreas (SOARES, OHAYON e ROSENBERG, 2009). Isto é, profissionais que nem sempre apresentam conhecimentos administrativos. Oliveira et al (1995) apud Soares, Ohayon e Rosenberg $(2009$, p. 2) defendem, contudo, que isso "não deve desestimular a busca de um melhor conhecimento sobre o trabalho do administrador, bem como suas habilidades e desempenho".

Isto posto, o gestor público assume um compromisso fundamental com a sociedade e com o desenvolvimento do país, ao se tornar responsável pelo bom funcionamento das organizações públicas. Albarello (2006, p. 52) explica que "a visão do administrador público se concentra na qualidade da prestação de serviços, sendo que os objetivos e respectivos resultados devem estar relacionados aos interesses sociais".

Para Barros (2009, p. 7), “o gestor público tem o papel de integrar sua equipe, exigindo eficiência e eficácia na prestação de serviços, agregando novos valores à administração pública em prol de serviços públicos de qualidade”. No Quadro 1 são descritas as quatro etapas do ciclo de programas sociais propostas por Jannuzzi (2005) e como devem ser os indicadores em cada uma destas etapas. Observa-se que, no caso da avaliação, estes indicadores devem revelar a eficácia e a efetividade dos programas.

$\mathrm{Na}$ avaliação de programas sociais (dentre as quais se inclui as políticas no âmbito da educação), Mourão (2007) também apontou ser importante a definição de indicadores, que devem ser objetivamente mensuráveis ou verificáveis, para de fato avaliar os resultados obtidos. Para essa autora, os indicadores são "medidas explícitas e objetivamente mensuráveis de mudanças induzidas" (p. 6). Cita ainda que existem vários critérios de avaliação, cada qual 
requerendo um enfoque diferente, como por exemplo, a eficiência, a eficácia e a efetividade. Rua (2009) realiza uma distinção conceitual entre eficiência, eficácia e efetividade, enquanto a primeira trata de processos, a segunda se ocupa de resultados, e a terceira por fim analisa impactos.

Quadro 1 Etapas do ciclo de programas sociais

\begin{tabular}{|c|c|c|}
\hline Etapa & Tipos e propriedades & Fonte de dados predominante \\
\hline $\begin{array}{l}\text { Elaboração do diagnóstico } \\
\text { Indicadores que permitam } \\
\text { "retratar" a realidade social }\end{array}$ & $\begin{array}{l}\text { Amplo escopo temático } \\
\text { Ampla desagregabilidade } \\
\text { geográfica e populacional } \\
\text { Validade de Constructo } \\
\text { Boa confiabilidade }\end{array}$ & $\begin{array}{l}\text { Censos demográficos } \\
\text { Pesquisas amostrais }\end{array}$ \\
\hline $\begin{array}{l}\text { Formulação de programas } \\
\text { E seleção de alternativas } \\
\text { Indicadores que orientem } \\
\text { objetivamente a tomada de } \\
\text { decisão }\end{array}$ & $\begin{array}{l}\text { Indicadores sintéticos } \\
\text { Indicadores multicritérios } \\
\text { Tipologias de situações } \\
\text { sociais }\end{array}$ & $\begin{array}{l}\text { Censos demográficos } \\
\text { Pesquisas amostrais }\end{array}$ \\
\hline $\begin{array}{l}\text { Implementação/Execução } \\
\text { Indicadores que permitam } \\
\text { "filmar" o processo de } \\
\text { implementação dos } \\
\text { programas formulados e a } \\
\text { eficiência }\end{array}$ & $\begin{array}{l}\text { Esforço (insumos/processos) } \\
\text { Atualidade/Regularidade } \\
\text { Sensibilidade } \\
\text { Especificidade }\end{array}$ & $\begin{array}{l}\text { Registros administrativos } \\
\text { Registros gerados nos } \\
\text { procedimentos dos próprios } \\
\text { programas }\end{array}$ \\
\hline $\begin{array}{l}\text { Avaliação } \\
\text { Indicadores que permitam } \\
\text { "revelar" a eficácia e } \\
\text { efetividade social dos } \\
\text { programas }\end{array}$ & $\begin{array}{l}\text { Resultados e impactos } \\
\text { Distância das metas (déficits } \\
\text { sociais) } \\
\text { Tipologias (boas práticas, etc) }\end{array}$ & $\begin{array}{l}\text { Pesquisas amostrais } \\
\text { Registros administrativos } \\
\text { Grupos focais } \\
\text { Pesquisas de egressos e de } \\
\text { participantes no programa }\end{array}$ \\
\hline
\end{tabular}

Fonte: Jannuzzi (2005, p. 148).

Como atribuições, Sachs, Lopes e Dowbor (2010) apud Reis e Matos (2012, p. 299) consideram que "o gestor público é o responsável por assessorar, planejar, tramitar nos processos deliberativos e decisórios, coordenar ações e avaliar programas e políticas públicas [...]”. Este compromisso do gestor público com a qualidade do serviço público é reflexo da Reforma Gerencial do Estado Brasileiro, que propõe a substituição do modelo burocrático pela moderna administração gerencial na administração pública.

Neste sentido, Rios (2011, p. 15) analisa que o conceito de foco no cliente foi transposto para a esfera pública como "administração voltada para o cidadão". Conforme Bergue (2010 apud RIOS, 2011), o novo modelo de gestão pública abriu as portas para conceitos e práticas gerenciais, como gestão pela qualidade, produtividade, economicidade, racionalização, desempenho, prestação de contas, planejamento estratégico, gestão por programas, ouvidorias etc. 
Com base em Rodrigues (2011, p. 46), o modelo dos ciclos (ou processos de gestão) das políticas públicas vem "sendo amplamente discutido pelos especialistas como forma simples de compreender o processo de formação das políticas". Desse modo, as políticas públicas são vistas como um processo formado por diferentes etapas que implicam em sistemas complexos de decisões e ações que tem por finalidade atender as demandas e interesses da sociedade.

\subsection{EVASÃO, RETENÇÃO E DIPLOMAÇÃO: BREVES CONSIDERAÇÕES}

Gaioso (2005) explica que a retenção ocorre quando o aluno permanece na universidade por mais tempo do que o normal do curso. Já a evasão ocorre quando o aluno deixa o curso de graduação sem concluí-lo. Segundo Silva (2011) e Colvero e Jovino (2014), há três tipos de evasão no ensino superior: a microevasão (evasão do curso), a mesoevasão (evasão da instituição) e a macroevasão (evasão do sistema universitário).

Em outras palavras, para Colvero e Jovino (2014), na microevasão o aluno se desliga do seu curso e ingressa em outro curso na mesma instituição, o que gera um déficit apenas ao curso; na mesoevasão ocorre a perda definitiva do vínculo institucional, o que gera déficit não apenas para o curso, como também para a instituição de ensino; já na macroevasão ocorre o desligamento total com o sistema superior de ensino, pela saída ou abandono dos estudos.

Esse é um dos fenômenos alvo de preocupação do plano nacional de assistência estudantil (PNAES) que tem por objetivos democratizar as condições de permanência dos jovens na educação superior pública federal; minimizar a desigualdade social e regional; agir preventivamente nas situações de retenção e evasão; viabilizar a igualdade de oportunidades, promover a inclusão social pela educação; e contribuir para a melhoria do desempenho acadêmico (Decreto ${ }^{\circ}$ 7.234/2010).

Silva, Benetti e Cabral (2015) alertam para a existência de uma diversidade de enfoques sobre o assunto da evasão por ser um fenômeno complexo influenciado por fatores internos e externos às instituições de ensino e que não se restringem só a aspectos acadêmicos. Cunha, Nascimento e Durso (2016) sustentam que a escolha e efetiva conclusão de um curso universitário afeta significativamente não só o estudante mas a sociedade que pode ter na evasão e insuficiência de retenção a perda de mais um profissional qualificado.

Para Cunha, Nascimento e Durso (2016), os investimentos despendidos na formação de um estudante que possa vir a evadir acabam sendo perdidos sem possibilidade de retorno visto que outro estudante não poderá dispor do mesmo. Nesse sentido, considerando as 
possíveis perdas anuais em função da evasão dos estudantes e consequente agravamento do prejuízo social torna-se relevante investigar seus índices e causas bem como as práticas de retenção.

Além da relevância e atualidade do tema, tendo em vista que não se pode falar em sucesso na democratização de ensino sem um esforço paralelo para viabilizar a permanência dos alunos (RIOS, 2011), pretende-se adicionar novo ângulo a essa pesquisa: o olhar do administrador. Assim, comparando-se as pesquisas em áreas tais como Educação (MALACARNE, 1997; ARAÚJO e LEITE, 2011; FERNANDES, 2012; ALVES, 2013; ASSIS, 2013; RAMALHO, 2013; SINDER e PEREIRA, 2013), Psicologia Social (MOURÃO, 2007), pretende-se contribuir com os estudos na área de Administração e Gestão Pública ou Políticas Públicas (JANNUZZI, 2005; ARAÚJO e BEZERRA, 2007; ALVES, 2010; ALVES, 2011; ARAÚJO, 2011; RIOS, 2011; CARVALHO, 2013), considerando o papel estratégico deste profissional nas organizações, sejam públicas ou privadas.

\section{MÉTODO}

Com a finalidade de atender ao objetivo proposto nesta pesquisa de analisar as ocorrências de evasão, retenção e colação de grau de estudantes de uma instituição federal de ensino, considerou-se adequada a realização de um estudo de caso, com uma abordagem quali-quantitativa, e de caráter exploratório-descritivo.

Assim, quanto aos procedimentos, essa pesquisa trata-se de um estudo de caso definido por Yin (1990) como mais adequado quando se pretende a investigação do fenômeno dentro de seu contexto real. Quanto à abordagem do problema, classifica-se como qualiquantitativa, visto que, para Minayo (1994), o conjunto de dados quantitativos e qualitativos não se opõem, mas se complementam. A organização objeto desse estudo foi uma instituição pública de ensino, multicampi, formada por dez unidades acadêmico-administrativas das quais participaram 543 estudantes.

Cabe destacar que esse trabalho é um recorte de dissertação, na qual consta a versão completa do instrumento de pesquisa, contudo para o objetivo desse estudo a coleta de dados foi realizada, primeiramente, uma pesquisa bibliográfica em sites e documentos da instituição. Após foi aplicado um questionário semi estruturado com 24 questões abertas e fechadas referentes à trajetória acadêmica do estudante, conforme apresentado no Quadro 2, destinado aos beneficiários do Plano de Permanência no período 2009-2015. 
Quadro 2 Instrumento de pesquisa

\begin{tabular}{|c|c|}
\hline Categoria/Subcategoria & Questões \\
\hline \multirow{4}{*}{ Dados Específicos (perfil) } & Idade \\
\cline { 2 - 2 } & Sexo \\
\cline { 2 - 2 } & Estado Civil \\
\cline { 2 - 2 } & Etnia \\
\cline { 2 - 2 } & Filhos \\
\cline { 2 - 2 } & Ocorrência e tipo de evasão \\
\cline { 2 - 2 } & Período da evasão \\
\hline \multirow{4}{*}{ Diplomão } & Motivo da evasão \\
\hline \multirow{5}{*}{ Retenção } & Tempo de conclusão do curso \\
\hline \multirow{5}{*}{} & Orimeiro emprego na área de formação \\
\cline { 2 - 2 } & Ocorrência de reprovação \\
\cline { 2 - 2 } & Motivo da reprovação \\
\cline { 2 - 2 } & Ocorrência de dificuldade de aprendizagem \\
\cline { 2 - 2 } & Descrição da dificuldade de aprendizagem \\
\cline { 2 - 2 } & Ocorrência de trancamento \\
\cline { 2 - 2 } & Motivo do trancamento \\
\cline { 2 - 2 } & Ocorrência de reopção \\
\cline { 2 - 2 } & Curso anterior a reopção \\
\cline { 2 - 2 } & Ocorrência da conclusão do curso optado \\
\hline
\end{tabular}

Fonte: Elaborado pelos autores.

A tabulação dos dados foi feita por meio Microsoft Excel procedendo-se primeiramente à análise de estatísticas descritivas e análise de conteúdo pelo método de Bardin (2009), partindo-se para interpretação e análise destes resultados e posteriormente as conclusões.

\section{ANÁLISE DOS RESULTADOS}

\subsection{PERFIL DOS RESPONDENTES}

Nas primeiras cinco questões do questionário, agrupadas sobre dados específicos do perfil tem-se as questões idade, sexo, estado civil, raça/cor/etnia e filhos, apresentados na Tabela 1 a fim de delinear o perfil dos alunos respondentes.

Observa-se que os alunos beneficiários são em sua maioria: jovens de até 25 anos $(55,25 \%)$, do sexo feminino $(60,04 \%)$, solteiros $(79,01 \%)$, brancos $(72,56 \%)$ e sem filhos $(83,43 \%)$. Cabe ressaltar que este perfil representa a população de beneficiários do Plano de Permanência da instituição, pelo alcance da amostra mínima calculada.

Também houve predominância destas características na pesquisa nacional: 75\% dos universitários são jovens na faixa etária de até 24 anos, 53,5\% dos estudantes são mulheres, $86,6 \%$ são solteiros, $54 \%$ são da raça/cor/etnia branca, e $90,8 \%$ não têm filhos (ANDIFES, 2011). 
Tabela 1 Perfil dos alunos

\begin{tabular}{lcc}
\hline Variável & Frequência & Percentual \\
\hline IDADE & & \\
\hline até 25 anos & $\mathbf{3 0 0}$ & $\mathbf{5 5 , 2 5 \%}$ \\
\hline 26 a 30 anos & 145 & $26,70 \%$ \\
\hline 31 a 35 anos & 45 & $8,29 \%$ \\
\hline 36 a 40 anos & 23 & $4,24 \%$ \\
\hline acima de 40 anos & 30 & $5,52 \%$ \\
\hline Total & 543 & $100,00 \%$ \\
\hline SEXO & & \\
\hline Feminino & $\mathbf{3 2 6}$ & $\mathbf{6 0 , 0 4 \%}$ \\
\hline Masculino & 217 & $39,96 \%$ \\
\hline Total & 543 & $100,00 \%$ \\
\hline ESTADO CIVIL & & \\
\hline Solteiro(a) & $\mathbf{4 2 9}$ & $\mathbf{7 9 , 0 1 \%}$ \\
\hline Casado(a) & 54 & $9,94 \%$ \\
\hline União Estável & 49 & $9,02 \%$ \\
\hline Separado(a) & 10 & $1,84 \%$ \\
\hline Viúvo(a) & 1 & $0,18 \%$ \\
\hline Total & 543 & $100,00 \%$ \\
\hline RAÇA/COR/ETNIA & & \\
\hline Branca & $\mathbf{3 9 4}$ & $\mathbf{7 2 , 5 6 \%}$ \\
\hline Parda & 86 & $15,84 \%$ \\
\hline Negra & 41 & $7,55 \%$ \\
\hline Amarela & 3 & $0,55 \%$ \\
\hline Indígena & 2 & $0,37 \%$ \\
\hline Não declarada & 17 & $3,13 \%$ \\
\hline Total & 543 & $100,00 \%$ \\
\hline FILHOS & & \\
\hline Não tenho & $\mathbf{4 5 3}$ & $\mathbf{8 3 , 4 3 \%}$ \\
\hline Um & 50 & $9,21 \%$ \\
\hline Dois ou mais & 40 & $7,37 \%$ \\
\hline Total & 543 & $100,00 \%$ \\
\hline & & \\
\hline & & \\
\hline & & \\
\hline
\end{tabular}

Fonte: Dados da pesquisa.

Sobre o perfil dos alunos beneficiários da insituição, chamou a atenção o elevado percentual de autodeclarados brancos. Esta situação se repetiu - muito embora em um percentual menor - na pesquisa nacional. No relatório da pesquisa nacional destaca-se, contudo, que o percentual de estudantes da raça/cor/etnia negra tem aumentado: de 5,9\% em 2004 para 8,7\% em 2010 (ANDIFES, 2011, p.22).

Esta nova configuração é resultante, sobretudo, da institucionalização nestes últimos anos das várias políticas de inclusão, em especial das várias modalidades de ações afirmativas e também do programa de expansão das Universidades Federais. $\mathrm{O}$ aumento do universo de estudantes de raça/cor/etnia preta e parda, majoritariamente nas classes $\mathrm{C}, \mathrm{D}$ e E, evidencia 
o importante papel dessas políticas na democratização do acesso à universidade pública (ANDIFES, 2011, p. 22).

A despeito disso, a pesquisa nacional traz um dado negativo, ao alertar para a diminuição da população indígena nas universidades: enquanto em 2004 era de 2\%, em 2010 representava apenas $0,9 \%$ (ANDIFES, 2011, p.22).

Constata-se também no perfil que, apesar de 83,43\% não terem filhos, 90 alunos $(16,58 \%)$ possuem um ou mais filhos. Segundo a pesquisa nacional do perfil, o percentual de estudantes com filhos tem diminuído e reflete a mudança na configuração das famílias da sociedade brasileira, apresentada pelo Censo 2010 (ANDIFES, 2011, p. 24). Todavia, dentre os alunos com filhos, é elevado o percentual dos que utilizam os serviços de creche $(43,4 \%)$ oferecidos pelas Universidades Federais, demonstrando a importância da universalização deste serviço (ANDIFES, 2011, p. 25).

\subsection{EVASÃO}

Sobre as questões relacionadas à evasão foram investigadas a ocorrência, o tipo de evasão e a motivação para tal. Na Tabela 2 estão elencadas as opções apontadas pelos estudantes que mais correspondia à sua realidade.

Tabela 2 Ocorrência e tipo de evasão

\begin{tabular}{cccc}
\hline Tipo de evasão & Frequência & $\mathbf{\%}$ Total & \% Evasão \\
\hline Não se aplica & 473 & $87,11 \%$ & - \\
\hline $\begin{array}{c}\text { Desligou-se de um curso e ingressou em outro curso na } \\
\text { mesma instituição }\end{array}$ & 22 & $4,05 \%$ & $31,43 \%$ \\
\hline $\begin{array}{c}\text { Desligou-se para ingressar em outra instituição de } \\
\text { ensino }\end{array}$ & $\mathbf{3 8}$ & $\mathbf{7 , 0 0 \%}$ & $\mathbf{5 4 , 2 9 \%}$ \\
\hline $\begin{array}{c}\text { Desligou-se totalmente do sistema superior de ensino, } \\
\text { pela saída ou abandono dos estudos }\end{array}$ & 10 & $1,84 \%$ & $14,29 \%$ \\
\hline Total & 543 & $100,00 \%$ & $100,00 \%$ \\
\hline
\end{tabular}

Fonte: Dados da pesquisa.

Visualiza-se na Tabela 2 que em, 87,11\% dos casos não ocorreu evasão. Dentre os casos de evasão, o maior índice (54,29\%) se refere ao desligamento de alunos para ingressar em outra instituição de ensino (transferência externa). Na sequencia, os estudantes foram questionados sobre período de evasão, isto é, em que momento do curso o aluno evadiu. A partir das respostas sistematizadas verificou-se que em $87,48 \%$ dos casos não se aplica a evasão. Contudo, dentre os casos de evasão, constata-se que os momentos igualmente críticos 
são o início $(48,53 \%)$ e o meio do curso (48,53\%), que juntos representam 97,06\% dos casos contra os $2,94 \%$ que ocorreram ao final do curso.

Por fim, o aluno deveria indicar os motivos da evasão. Verifica-se que houveram 73 respostas válidas $(13,44 \%)$ e 470 em branco $(86,56 \%)$, que deram origem às categorias que emergiram das respostas: Pessoal (42), Institucional (15), Cidade (8), Não se aplica (12) e Outros (2), conforme relatos representativos no Quadro 3.

Quadro 3 Motivos para a evasão

\begin{tabular}{|c|c|c|c|}
\hline Categoria & Subcategoria & Entrevistado & Relato \\
\hline \multirow{7}{*}{ Pessoal } & Financeiros & $E 376 ; E 430$ & $\begin{array}{l}\text { Poucos recursos financeiros para se } \\
\text { manter apenas estudando [...] }\end{array}$ \\
\hline & Familiar & $E 322 ; E 403$ & $\begin{array}{l}\text { Distância do campus da minha terra } \\
\text { natal }\end{array}$ \\
\hline & $\begin{array}{l}\text { Falta de } \\
\text { afinidade }\end{array}$ & $E 293 ; E 370$ & $\begin{array}{l}\text { Desistência do curso por não ter se } \\
\text { identificado com a profissão }\end{array}$ \\
\hline & Transferência & E269; E319 & $\begin{array}{l}\text { Optei por uma universidade federal do } \\
\text { meu estado }(M G) \text {, eu já esperava voltar } \\
\text { para meu estado quando ingressei. [...] }\end{array}$ \\
\hline & Distância & E482 & $\begin{array}{l}\text { Por ter passado em concurso público, } \\
\text { sendo obrigado a mudar de município e } \\
\text { evadir do curso. }\end{array}$ \\
\hline & $\begin{array}{l}\text { Reopção de } \\
\text { curso }\end{array}$ & $E 42$ & $\begin{array}{l}\text { Troquei de curso na mesma instituição } \\
\text { pois já era minha decisão antes mesmo de } \\
\text { ingressar [...] }\end{array}$ \\
\hline & Saúde & E132 & Depressão \\
\hline \multirow{2}{*}{ Institucional } & $\begin{array}{l}\text { Insatisfação } \\
\text { curso e/ou } \\
\text { instituição }\end{array}$ & E19; E305 & $\begin{array}{l}\text { Professores, estrutura curricular, falta de } \\
\text { incentivo a pesquisa, etc }\end{array}$ \\
\hline & $\begin{array}{l}\text { Assistência } \\
\text { Estudantil }\end{array}$ & E325: E346 & $\begin{array}{l}\text { Falta de programas assistências a nivel } \\
\text { socioeconomico, bolsas, auxilios, } \\
\text { trabalhos remunerados }\end{array}$ \\
\hline \multirow[t]{2}{*}{ Cidade } & Estrutura & $E 363$ & $\begin{array}{l}\text { Dificuldades na permanência na cidade, } \\
\text { pois tudo era difícil moradia, ônibus até a } \\
\text { universidade [...] }\end{array}$ \\
\hline & Falta trabalho & E512 & $\begin{array}{l}\text { Por situação financeira, e poucas } \\
\text { possibilidades de emprego na cidade [...] }\end{array}$ \\
\hline
\end{tabular}

Fonte: Dados da pesquisa.

Assim, constata-se com as informações contidas no Quadro 3 verifica-se que dentre os motivos para evadir, a categoria pessoal revelou-se mais representativa com 42 ocorrências. Essas ocorrências se distribuíram nas subcategorias: financeiros (17), familiar (10), falta de afinidade com o curso e/ou com a profisssão (5), transferência (4), distância (3), reopção de curso (3) e saúde do aluno (3), Dentro da subcategoria referente às dificuldades financeiras englobou-se a necessidade e a dificuldade em conciliar estudo com trabalho. Observou-se 
também a combinação desta subcategoria com questões como a falta de empresa na cidade do campus, a necessidade de sustentar os filhos ou a dificuldade de ser sustentado pela família. Destaca-se que reopção de curso e transferência são tipos de evasão, e não propriamente as motivações que levaram à evasão, que é a proposta da questão.

Furtado e Alves (2012) destacaram entre as variáveis mais relevantes para explicar a evasão, o município de residência e a sua provável associação com a distância do Campus. Tais fatores segundo os autores conteriam dois elementos: os custos de transportes e a facilidade de acesso. A distância, neste caso, pode estar revelando a capacidade financeira da família e/ou às condições familiares e de serviços públicos de educação para o desenvolvimento da formação do aluno. Complementar a isso, Cesar e Bruno-Faria (2013) apontam diferentes motivações para a evasão encontrados na literatura, dentre elas aspectos da vida pessoal ou familiar do estudante, aspectos relacionados à escolha e expectativa do ingresso com o curso e com a universidade, incompatibilidade entre os horários de estudos com as demais atividades, como, por exemplo, o trabalho; aspectos familiares como, por exemplo, responsabilidades com filhos e dependentes, apoio familiar quanto aos estudos.

Na categoria "Institucional” tem-se 15 ocorrências, nas subcategorias Insatisfação com o curso e/ou instituição (11) e Assistência Estudantil (5). Para Slhessarenko et al. (2014) a redução da evasão esta diretamente relacionada a adoção de estratégias que visem a melhoria da qualidade de ensino e serviços ofertados, assim como manter os estudantes dentro do sistema educacional. Os autores afirmam ainda que as causas de evasão relativas ao ambiente interno da instituição podem ser solucionadas por meio de capacitação da formação didáticopedagógica, através de programas de treinamento para os professores e da revisão curricular do curso adequando as disciplinas e seus enfoques de acordo com as necessidades dos alunos e do mercado de trabalho.

\subsection{DIPLOMAÇÃO}

No que tange à questão da diplomação, abordou-se o tempo de conclusão do curso pelo aluno e primeiro emprego na área de formação. Sobre a primeira questão verificou-se que os alunos que não concluíram o curso representam $62,80 \%$ e os formados somam $37,20 \%$ $(22,47 \%$ na duração normal do curso; $6,81 \%$ em um semestre além da duração normal; e $7,92 \%$ em dois semestres além da duração normal). À primeira vista, o percentual de não formados pode parecer negativo, contudo, os dados anteriores da pesquisa ajudam a esclarecer que, em sua maioria, se referem a alunos ainda em formação. Outro dado relevante foi o de 
que os alunos beneficiários estão conseguindo se formar na duração normal do curso (representam $22,47 \%$ do total de respondentes e $60,40 \%$ do total de formados. Na Tabela 3 descreve-se os resultados em relação ao tempo necessário para conseguir o primeiro emprego na área de formação após ter se formado.

Tabela 3 Primeiro emprego na área de formação

\begin{tabular}{cccc}
\hline Emprego na área & Frequência & \% Total & \% na área \\
\hline não se aplica & 444 & $81,77 \%$ & - \\
\hline até 6 meses & $\mathbf{5 8}$ & $\mathbf{1 0 , 6 8 \%}$ & $\mathbf{5 8 , 5 9 \%}$ \\
\hline de 6 meses a 1 ano & 17 & $3,13 \%$ & $17,17 \%$ \\
\hline de 1 ano a 2 anos & 14 & $2,58 \%$ & $14,14 \%$ \\
\hline mais de 2 anos & 10 & $1,84 \%$ & $10,10 \%$ \\
\hline Total & 543 & $100,00 \%$ & $100,00 \%$ \\
\hline
\end{tabular}

Fonte: Dados da pesquisa.

Diante dos dados expostos na Tabela 5 , evidencia-se que $81,77 \%$ dos alunos marcaram "não se aplica", um percentual mais elevado do que o obtido na questão anterior $(62,80 \%)$, pois possivelmente aos alunos em formação se somaram os alunos que ainda não conseguiram trabalho na profissão no qual se formaram. A despeito disto, observa-se também que o maior percentual de alunos conseguiu colocação em sua área em pouco tempo (em até 6 meses depois de formados), representando $10,68 \%$ em relação ao total de respostas e $58,59 \%$ em relação ao total de alunos que conseguiram o primeiro emprego na área de formação).

Em relação à Diplomação, a pesquisa mostra dados positivos: dentre os alunos formados, $60,40 \%$ conseguiram se formar na duração normal do curso e 58,59\% conseguiram um emprego na área de formação em até 6 meses.

\subsection{RETENÇÃO}

Quanto à retenção, investigou-se sobre a ocorrência e motivo de reprovação, ocorrência e descrição da dificuldade de aprendizagem, ocorrência e motivo de trancamento bem como as questões relacionadas à reopção e conclusão de curso. Os resultados pertinentes a ocorrência de reprovação evidenciam que 32,60\% dos alunos não apresentam reprovações no histórico, porém os alunos que apresentam algum tipo de reprovação somam $67,40 \%$ (46,22\% por nota; $5,16 \%$ por frequência; e $16,02 \%$ por nota e por frequência), sendo um dado preocupante considerando os critérios acadêmicos para manutenção do aluno no Plano de Permanência: 
III. apresentar desempenho acadêmico satisfatório, obtendo aprovação em, no mínimo, $60 \%$ (sessenta por cento) dos créditos matriculados no semestre anterior, e não apresentar reprovação por frequência em nenhuma disciplina no semestre anterior (Resolução nº 84/2014, Art. 14)

Isto é, além de provocar a retenção, a reprovação pode implicar no desligamento do Plano de Permanência, automático no caso de frequência e, no caso de reprovação por nota, se não for alcançado $60 \%$ de aproveitamento. $\mathrm{Na}$ sequência, os estudantes foram questionados sobre o motivo da reprovação. Foram obtidas 325 respostas (representam 59,85\% do total de participantes da pesquisa), no Quadro 4 apresenta-se uma síntese dos relatos.

Quadro 4 Motivos da reprovação

\begin{tabular}{|c|c|c|c|}
\hline Categoria & Subcategoria & Entrevistado & Relato \\
\hline \multirow{9}{*}{ Pessoal } & Adaptação & E449 & $\begin{array}{l}\text { Depressão, dificuldade de socialização, } \\
\text { dificuldade de aculturação, dificuldade de } \\
\text { ajustamento ao modelo de ensino. }\end{array}$ \\
\hline & Saúde & E96 & $\begin{array}{l}\text { Transtorno de deficit de atenção } \\
\text { diagnosticado e em tratamento. }\end{array}$ \\
\hline & Familiar & $E 22$ & Nascimento de minha filha mais nova. \\
\hline & & E165 & Doença na família e perda de um familiar. \\
\hline & $\begin{array}{l}\text { Organização } \\
\text { do tempo }\end{array}$ & E514 & $\begin{array}{l}\text { Falta de organização nos estudos diários, } \\
\text { acúmulo de matéria [...] }\end{array}$ \\
\hline & Financeiras & E313 & $\begin{array}{l}\text { Condições Financeiras de ir ou de comprar o } \\
\text { material requisitado para todas as disciplinas. }\end{array}$ \\
\hline & $\begin{array}{l}\text { Dificuldade } \\
\text { de conciliar }\end{array}$ & E193 & $\begin{array}{l}\text { Tinha que me virar em estudar e trabalhar, } \\
\text { cuidar da casa e da familia }\end{array}$ \\
\hline & $\begin{array}{ll}\begin{array}{l}\text { Base } \\
\text { ensino }\end{array} & \text { de } \\
\end{array}$ & E120 & Ensino básico muito fraco. \\
\hline & Faltou estudo & $E 80$ & Falta de estudo suficiente \\
\hline \multirow{3}{*}{ Institucional } & $\begin{array}{l}\text { Administrativ } \\
\mathrm{o}\end{array}$ & E105 & Greve da Biblioteca \\
\hline & Pedagógica & $E 155$ & Carga horaria excessiva, conteúdo pesado. \\
\hline & & E427 & $\begin{array}{l}\text { Dificuldade em compreender a matéria e o } \\
\text { professor. }\end{array}$ \\
\hline \multirow{2}{*}{ Cidade } & Transporte & $E 380$ & Horário do ônibus complicado. \\
\hline & Cultural & E132 & [...] a questão da discriminação. \\
\hline Outros & Tipo & E474 & Por nota. \\
\hline
\end{tabular}

Fonte: Dados da pesquisa.

Verificou-se também que as questões didático-pedagógicas lideraram as motivações para as reprovações. Cabe explicar que, nesta e em outras questões abertas, optou-se pela não indicação de frequência das respostas, pelo volume de respostas por questão (543) e o fato de que muitas respostas se enquadram em mais de uma categoria. 
Sobre a ocorrência de dificuldade de aprendizagem, constatou-se que 58,93\% consideram não possuir e $41,07 \%$ dos alunos manifestaram possuir alguma dificuldade de aprendizagem. Dentre os que sinalizaram positivamente nessa questão, identificou-se que novamente as questões didático-pedagógicas foram as mais citadas. No Quadro 5 apresenta-se algumas das principais dificuldades de aprendizagem relatadas.

Quadro 5 Dificuldades de Aprendizagem

\begin{tabular}{|c|c|c|c|}
\hline Categoria & Subcategoria & Entrevistado & Relato \\
\hline \multirow{9}{*}{ Pessoal } & Adaptação & E479 & $\begin{array}{l}\text { Por ter terminado o ensino médio a muito tempo } \\
\text { tive um pouco de dificuldade [...] }\end{array}$ \\
\hline & Base de ensino & E454 & $\begin{array}{l}\begin{array}{l}\text { Ensino básico fraco, o qual refletiu no } \\
\text { desemprenho acadêmico }\end{array} \\
\end{array}$ \\
\hline & Desmotivação & E244 & falta [...] mais dedicação minha $[\ldots]$ \\
\hline & $\begin{array}{l}\text { Organização } \\
\text { do tempo }\end{array}$ & E242 & $\begin{array}{l}\text { Encontrar a forma mais correta de organizar } \\
\text { minha rotina de estudos e conciliá-la com as aulas } \\
\text { [...]. }\end{array}$ \\
\hline & $\begin{array}{l}\text { Dificuldade de } \\
\text { conciliar }\end{array}$ & E185 & $\begin{array}{l}\text { [...] mas estudar fora do horário de aula pra quem } \\
\text { tem que trabalhar é quase impossivel. }\end{array}$ \\
\hline & $\begin{array}{l}\text { Deficiência } \\
\text { física }\end{array}$ & E5; E139 & [...] por ser deficiente auditiva [...] \\
\hline & Linguagem & E509 & Leitura de textos acadêmicos, escrita acadêmica. \\
\hline & Cálculo/Exata & E469 & $\begin{array}{l}\text { Principalmente em disciplinas que envolvem } \\
\text { muitos cálculos. }\end{array}$ \\
\hline & Assimilação & $E 74 ; E 260$ & Dificuldade em fixar o conteúdo \\
\hline \multirow{5}{*}{$\begin{array}{l}\text { Instituciona } \\
1\end{array}$} & Administrativo & E346 & $\begin{array}{l}\text { por que horarios tanto de atendimento quanto de } \\
\text { atividades extras são nos turnos manhã e tarde, } \\
\text { justamente quando estamos trabalhando? }\end{array}$ \\
\hline & Pedagógica & $\begin{array}{l}\text { E65; E142: } \\
\quad \text { E145 }\end{array}$ & $\begin{array}{l}\text { Dificuldade de relacionamento com um(a) } \\
\text { professor(a) [...] nem ele(a) sabia explicar } \\
\text { matéria que aplicava. }\end{array}$ \\
\hline & Suporte & E135 & $\begin{array}{l}\text { Não existe curso de nivelamento, e as monitorias } \\
\text { so começaram depois que já teve ou está proxima } \\
\text { às provas }\end{array}$ \\
\hline & $\begin{array}{l}\text { Práticas/Estági } \\
\mathrm{o}\end{array}$ & E204 & $\begin{array}{l}\text { excesso de slides em algumas aulas tornou mais } \\
\text { complicado o entendimento do conteúdo e também } \\
\text { por falta de aulas práticas. }\end{array}$ \\
\hline & $\begin{array}{l}\text { Componentes } \\
\text { curriculares }\end{array}$ & E343 & $\begin{array}{l}{[\ldots] \text { algumas disciplinas bases }[\ldots] \text { foram }} \\
\text { cortadas, e senti falta delas como base }[\ldots]\end{array}$ \\
\hline
\end{tabular}

Fonte: Dados da pesquisa.

Quando analisada a ocorrência de trancamento total e/ou parcial pelos alunos constatou-se que 78,64\% dos alunos não precisaram trancar a matrícula durante sua trajetória acadêmica. Aos alunos que responderam "sim" nessa questão, perguntou-se qual(is) o(s) motivo(s) do trancamento, considerando-se que o trancamento é um indicativo de retenção. 
Obteve-se 113 respostas válidas (20,81\% do total de alunos participantes). Os dados apresentados no Quadro 6 indicam alguns motivos de trancamento, constata-se que não houve preponderância significativa de nenhuma das categorias/subcategorias.

Quadro 6 Motivos do trancamento

\begin{tabular}{|c|c|c|c|}
\hline Categoria & Subcategoria & Entrevistado & $\begin{array}{r}\text { Relato } \\
\end{array}$ \\
\hline \multirow{10}{*}{ Pessoal } & Pessoais & E40 & $\begin{array}{l}\text { Por motivos religiosos, não faço aulas na } \\
\text { sextas-feiras a noite [...] }\end{array}$ \\
\hline & Saúde & E231 & $\begin{array}{l}\text { [...] de doenças, de minha parte e também } \\
\text { por uma filha que nasceu prematura e } \\
\text { necessitou de tratamento,em outra cidade. }\end{array}$ \\
\hline & Mobilidade/Intercâmbio & E82 & $\begin{array}{l}\text { [...] participei do programa ciência sem } \\
\text { fronteiras, logo tive de ficar um ano e meio } \\
\text { fora do país. }\end{array}$ \\
\hline & Organização do tempo & E351 & $\begin{array}{l}\text { Excesso de disciplinas durante o semestre, } \\
\text { para não sair prejudicada em várias, optei } \\
\text { por desistir de uma delas. }\end{array}$ \\
\hline & Dificuldade de conciliar & E265 & $\begin{array}{l}\text { Trancamento total, pela relação } \\
\text { trabalho/estudo. }\end{array}$ \\
\hline & $\begin{array}{l}\text { Evitar desligamento no } \\
\text { Plano de Permanência }\end{array}$ & $\mathrm{E} 50 ; \mathrm{E} 520$ & $\begin{array}{l}\text { - não perder a bolsa; } \\
\text { - não reprovar em mais disciplinas." }\end{array}$ \\
\hline & Distância & E124 & $\begin{array}{l}\text { Não quis mais fazer a cadeira porque era } \\
\text { de noite e eu morava afastada do centro. }\end{array}$ \\
\hline & Estágio & E434 & $\begin{array}{l}\text { Estar tendo que trabalhar e estagiar } \\
\text { cursando mais } 7 \text { disciplinas }\end{array}$ \\
\hline & Financeiros & E286; E512 & $\begin{array}{l}\text { Falta de dinheiro devido ao falecimento da } \\
\text { única pessoa que me auxiliava [...] }\end{array}$ \\
\hline & Transferência/Reopção & E376 & Transferência para outra Universidade. \\
\hline
\end{tabular}

Fonte: Dados da pesquisa.

Assim, em relação à retenção, os dados indicam que os alunos que apresentam algum tipo de reprovação somam $67,40 \%$ (46,22\% por nota, $5,16 \%$ por frequência e $16,02 \%$ por nota e por frequência), sendo um dado preocupante considerando os critérios acadêmicos de manutenção no Plano de Permanência, e como motivações destacam-se dificuldades didáticopedagógicas em relação aos docentes. Apesar disso, 58,93\% afirmaram não possuir dificuldades de aprendizagem. Com os dados apresentados verificou-se também que 78,64\% dos alunos não fizeram trancamento de matrícula e 91,16\% não fizeram reopção.

Rissi e Marcondes (2009) indicam que os fatores que levam a evasão, retenção e/ou reprovação em cursos de graduação podem estar associados a questões internas e externas ao curso pretendido. Dentre os fatores internos os atores destacam às questões acadêmicas como currículos desatualizados, a falta de clareza no projeto pedagógico do curso, desinteresse do docente em se atualizar e, além destes, que são inerentes ao aluno e a Instituição. Já dentre os 
fatores externos citam a qualidade do ensino da educação básica e também aqueles relacionados à desvalorização profissional. Em função disso, esses autores comentam que a influência dos índices de retenção e reprovação na evasão e com isso salientam a necessidade de atentar-se projetos pedagógicos dos cursos que devem ser objetos de acompanhamento e de autoavaliação buscando verificar se os conteúdos e as disciplinas atendem a necessidade de formação profissional e cidadã dos acadêmicos.

\section{CONCLUSÃO}

O objetivo desse estudo foi analisar as ocorrências de evasão, retenção e colação de grau de estudantes de uma instituição federal de ensino. Dessa forma, visando alcançar o objetivo proposto, realizou-se uma pesquisa de abordagem quali-quantitativa. Os resultados obtidos revelaram um baixo percentual de ocorrência de evasão, mas que ainda podem ser minimizados. Dentre os casos de evasão, o maior índice se refere à transferência de alunos para outra instituição de ensino, e os momentos críticos para a evasão foram o início e o meio do curso. Dentre as causas apontadas pelos alunos, ressaltam-se as de cunho pessoal, especialmente de ordem financeira e familiar.

Em relação a diplomação, os resultados demonstraram-se positivos, pois constatou-se que, dentre os alunos formados, a maioria concluiu o curso dentro do período estimado e conseguiu empregar-se na área de formação em até 6 meses. Já em relação à retenção, os resultados indicam uma situação mais preocupante, visto que a maioria dos alunos apresenta algum tipo de reprovação, seja por nota, frequência ou ambos. Dentre as motivações para a reprovação, destacam-se entre os estudantes dificuldades didático-pedagógicas em relação aos docentes. Esses dados carecem de atenção, pois a reprovação pode implicar em retenção e posteriormente na evasão e ambas as situações causam danos ao estudante e a sociedade. Ao estudante implica a manutenção no Plano de Permanência e a sociedade, os custos dos recursos dispendidos sem retorno.

Concluiu-se com o estudo que muitos fatores influem sobre a evasão, diplomação e retenção acadêmica. $\mathrm{O}$ sucesso e permanência dos estudantes podem estar atrelados a fatores pessoais, fatores didático-pedagógicos, desafios estruturais das cidades etc. Assim faz-se necessário o conhecimento, monitoramento e enfrentamento maciço dessas questões. Dessa forma, espera-se que essa pesquisa possa contribuir tanto para a atualização de dados e para a visualização de questões que carecem de estratégias de gestão pública, quanto para a expansão de pesquisas sobre a temática em meio cientifico. Constatou-se também, pelo 
volume considerável de participantes, que os alunos aderem quando se trata de avaliação na expectativa de produzir contribuições e melhorias. Sugere-se, com isso, que pesquisas futuras explorem essas questões em profundidade por meio de grupos focais que envolvam os acadêmicos e os gestores. Quanto às limitações da pesquisa, aponta-se a dificuldade na tabulação das questões abertas frente a quantidade de respostas obtidas.

\section{REFERÊNCIAS}

ALBARELLO, C. B. O papel do administrador na gestão pública. Revista de Administração, Frederico Westphalen, v. 5, n. 9, p. 49-71, dez./2006. Disponível em: $<$ http://revistas.fw.uri.br/index.php/revistadeadm/article/view/878/1353>. Acesso em:

ASSOCIAÇÃO NACIONAL DOS DIRIGENTES DAS INSTITUIÇÕES FEDERAIS DE ENSINO SUPERIOR. Fórum Nacional de Pró-Reitores de Assuntos Comunitários e Estudantis. Perfil Socioeconômico e Cultural dos Estudantes de Graduação das Universidades Federais Brasileiras. Brasília/DF. 2011. Disponível em:

$<$ http://www.andifes.org.br/wpcontent/files_flutter/1377182836Relatorio_do_perfi_dos_estudantes_nas_universidades_feder ais.pdf $>$. Acesso em: 8 jun. 2015.

BARDIN, L. Análise de conteúdo. 4.ed. Lisboa: Edições 70, 2009.

BARROS, C. M. Gestor público: uma análise das principais competências requeridas nos dias atuais. 2009. 42 p. Trabalho de conclusão de curso (Curso Intensivo de Pós-Graduação em Administração Pública)-Fundação Getúlio Vargas, Belo Horizonte, 2009. Disponível em: $<$ http://www.der.mg.gov.br/images/TrabalhosAcademicos/caetano $\% 20$ magalhaes $\% 20 \mathrm{de} \% 20$ barros\%20monografia.pdf $>$. Acesso em: 15 ago. 2015.

CESAR, C. E. F. da S.; BRUNO-FARIA, M. F. Causas da evasão em cursos de capacitação de técnicos em instituição de ensino superior. Revista de Gestão Universitária da América Latina, v. 6, n. 1, p. 287-309, jan. 2013.

COLVERO, R. B.; JOVINO, D. P. Evasão acadêmica nas IES do Brasil: uma análise do ano de 2010. Revista Argentina de Educación Superior, v. 6, n. 8, p. 62-85, jun. 2014.

CUNHA, J. V. A. da; NASCIMENTO, E. M.; DURSO, S. DE O. Razões e influências para a evasão universitária: um estudo com estudantes ingressantes nos cursos de Ciências Contábeis de instituições públicas federais da Região Sudeste. Advances in Scientific and Applied Accounting, v.9, n. 2, p.141-161, maio/ago. 2016.

FURTADO, V.V.A.; ALVES, T. W. Fatores determinantes da evasão universitária: uma análise com alunos da UNISINOS. Revista Contemporânea de Economia e Gestão. v. 10, n. 2, p. 115-129 jul/dez 2012. 
GAIOSO, N. P. L. O fenômeno da evasão escolar na educação superior no Brasil. 2005. 75 f. Dissertação (Mestrado em Educação) - Universidade Católica de Brasília, Brasília, 2005.

JANUZZI, P. de M. Indicadores para diagnóstico, monitoramento e avaliação de programas sociais no Brasil. Revista do Serviço Público, v. 56, n. 2, p. 137-160, abr/Jun. 2005.

MINAYO, M. C. S. (Org.). Pesquisa social: teoria, método e criatividade. 4.ed. Petrópolis: Vozes, 1994.

MOURÃO, L. Discussão metodológica sobre avaliação de programas sociais. In: XIV Encontro Nacional da Associação Brasileira De Psicologia Social (ABRAPSO), 2007, Rio de Janeiro. Anais... Rio de Janeiro: Campus da UERJ, 2007. Disponível em:

$<$ http://www.abrapso.org.br/siteprincipal/anexos/AnaisXIVENA/conteudo/pdf/trab_completo _298.pdf>. Acesso em: 9 jun. 2017.

PEIXOTO, M. C. L. (Org). Universidade e Democracia: experiências e alternativas para a ampliação do acesso à universidade pública brasileira. Belo Horizonte: E. UFMG, 2004.

REIS, R. C. S.; MATOS, C. R. N. Perfil do gestor público: elementos para formação e mudanças. In: $1^{a}$ Conferência Internacional de Estratégia em Gestão, Educação e Sistemas de Informação (I CIEGESI), 2012, Goiânia-GO. Anais... Goiânia: Universidade Estadual de Goiás, 2012. Disponível em: Acesso em: 15 ago. 2016.

RIOS, R. Avaliação do Programa Bolsas de Permanência da Universidade Federal do Pampa por seus usuários. 2011. 92 f. Monografia (Especialização em Gestão Pública)Universidade Federal de Santa Maria, Santa Maria, 2011.

RIOS, R.; COSTA, V. M. F.; SANTOS, L. A.; TOMAZZONI, G. C.; JANISSEK, J. A. Análise do plano de permanência dos estudantes nas instituições federais de ensino superior brasileiras. In: XVI Colóquio Internacional de Gestão Universitária (CIGU), 2016, Arequipa. Anais...Arequipa: CIGU, 2016. Disponível em:

$<$ https://repositorio.ufsc.br/xmlui/handle/123456789/171298> Acesso em: 9 jun. 2017.

RISSI, M. C.; MARCONDES, M. A. S. (orgs). Estudo sobre a reprovação e retenção nos cursos de graduação - 2009. Relatório. Londrina: UEL, 2011. Disponível em: < http://www.uel.br/proplan/LIVRO_CD_COMPLETO_Retencao_reprovacao.pdf $>$. Acesso em: 10 julho. 2017.

SILVA, L. H. S. Ensino, Retenção e Evasão. Rio de Janeiro, dez 2011. 1 diapositivo, color. Disponível em: <http://slideplayer.com.br/slide/2660073/>. Acesso em: 15 ago. 2015.

SLHESSARENKO, M.; GONÇALO, C. R.; BEIRA, J. C.; CEMBRANEL, P. A evasão na educação superior para o curso de bacharelado em sistema de informação. Revista de Gestão Universitária da América Latina, v. 7, n. 1, p. 128-147, jan. 2014.

SOARES, V. B.; OHAYON, P.; ROSENBERG, G. O Perfil e a formação do administrador público: uma análise curricular em seis instituições de ensino superior do Brasil. In: II Encontro de Ensino e Pesquisa Em Administração e Contabilidade, 2009, Curitiba. Anais... 
Curitiba: ANPAD, 2009. Disponível em:

$<$ http://www.anpad.org.br/diversos/trabalhos/EnEPQ/enepq_2009/ENEPQ178.pdf $>$. Acesso em 15 ago. 2015.

SILVA, F C.; BENETTI, G. M. F.; CABRAL, T. L. O. Evasão no ensino superior: a produção científica no colóquio internacional de gestão universitária. In: XV Colóquio Internacional de Gestão Universitária (CIGU), 2015, Mar del Plata - Argentina. Anais... Mar del Plata: CIGU, 2015. Disponível em: <https://repositorio.ufsc.br/xmlui/handle/123456789/135903> Acesso em: 9 jun. 2017.

UNIVERSIDADE FEDERAL DO PAMPA. Conselho Universitário. Resolução nº 84, de 30 de outubro de 2014. Aprova a Política de Assistência Estudantil. Bagé, 2014. Disponível em: <http://porteiras.r.unipampa.edu.br/portais/consuni/files/2010/06/Res._84_2014Pol\%C3\%ADtica-de- Assist\%C3\%AAncia-Estudantilb.pdf $>$. Acesso em: $\overline{6}$ mar. 2015.

YIN, R. K. Estudo de caso: planejamento e métodos. 2. ed. Porto Alegre: Bookman, 2001. 